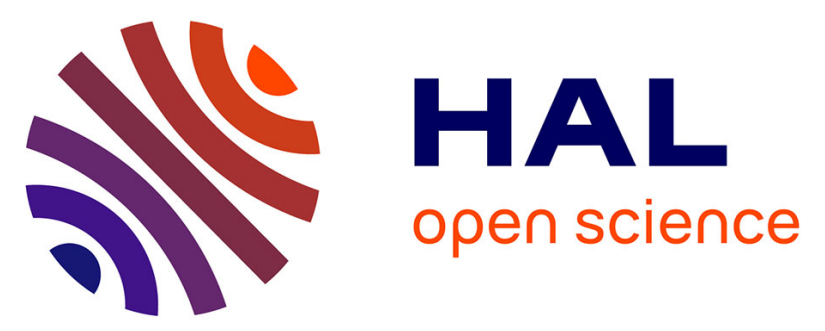

\title{
Monitoring of autogenous crack healing in cementitious materials by the nonlinear modulation of ultrasonic coda waves, 3D microscopy and X-ray microtomography
}

Benoit Hilloulin, Jean-Baptiste Legland, Elisabeth Lys, Odile Abraham, Ahmed Loukili, Frederic Grondin, Olivier Durand, Vincent Tournat

\section{To cite this version:}

Benoit Hilloulin, Jean-Baptiste Legland, Elisabeth Lys, Odile Abraham, Ahmed Loukili, et al.. Monitoring of autogenous crack healing in cementitious materials by the nonlinear modulation of ultrasonic coda waves, 3D microscopy and X-ray microtomography. Construction and Building Materials, 2016, 123, pp.143-152. 10.1016/j.conbuildmat.2016.06.138 . hal-01347514

\author{
HAL Id: hal-01347514 \\ https://hal.science/hal-01347514
}

Submitted on 21 Jul 2016

HAL is a multi-disciplinary open access archive for the deposit and dissemination of scientific research documents, whether they are published or not. The documents may come from teaching and research institutions in France or abroad, or from public or private research centers.
L'archive ouverte pluridisciplinaire HAL, est destinée au dépôt et à la diffusion de documents scientifiques de niveau recherche, publiés ou non, émanant des établissements d'enseignement et de recherche français ou étrangers, des laboratoires publics ou privés. 


\title{
Monitoring of autogenous crack healing in cementitious materials by the nonlinear modulation of ultrasonic coda waves, 3D microscopy and X-ray microtomography
}

\author{
Benoit Hilloulin ${ }^{\mathrm{a}, \mathrm{b}, *}$, Jean-Baptiste Legland ${ }^{\mathrm{c}}$, Elisabeth Lys ${ }^{\mathrm{d}}$, Odile Abraham ${ }^{\mathrm{c}}$, Ahmed Loukili ${ }^{\mathrm{a}}$, \\ Frédéric Grondin ${ }^{\mathrm{a}}$, Olivier Durand ${ }^{\mathrm{c}}$, Vincent Tournat ${ }^{\mathrm{e}}$ \\ a Institut de Recherche en Génie Civil et Mécanique (GeM), UMR-CNRS 6183, Ecole Centrale de Nantes, 1 rue de la Noë, 44321 Nantes, France \\ ${ }^{\mathrm{b}}$ Magnel Laboratory for Concrete Research, Ghent University, Technologiepark Zwijnaarde 904, B-9052 Ghent, Belgium \\ 'IFSTTAR, GERS, CS4, F-44344 Bouguenais Cedex, France \\ d SUBATECH, IN2P3, UMR CNRS 6457, Ecole des Mines de Nantes, 4 rue Alfred Kastler, 44307 Nantes Cedex, France \\ e LAUM, CNRS UMR 6613, Université du Maine, Av. O. Messiaen, 72085 Le Mans Cedex 9, France
}

In this work the non-destructive monitoring of the self-healing progress of cracked mortars is presented through the use of three combined methods: nonlinear Coda Wave Interferometry, 3D microscopy and Xray computed microtomography $(\mathrm{CT})$. The aim of the acoustic method is to compare, at various healing stages, both the ultrasonic velocity variations and decorrelation coefficients between a reference coda signal and a signal perturbed by a high level lower-frequency elastic wave. The decrease in the relative variation of the extracted nonlinearities demonstrates its ability to accurately monitor global crack filling. 3D microscopy also reveals this capability. Measurement results of these two techniques agree for the influence of age at cracking on healing potential. In reducing the voxel size to $12 \mu \mathrm{m}, \mathrm{X}$-ray CT images confirm the creation of localized bridges between crack faces and provide information on their location.
Keywords:

Self-healing

Concrete

Cracks

Ultrasonic wave speed

3D microscopy

X-ray microtomography

\section{Introduction}

Even if crack occurrence in concrete structures is taken into account during the design stage, cracks still generate considerable inspection and repair costs; moreover, they jeopardize structural durability since aggressive substances (liquid solutions, ions and

\footnotetext{
* Corresponding author at: Institut de Recherche en Génie Civil et Mécanique (GeM), UMR-CNRS 6183, Ecole Centrale de Nantes, 1 rue de la Noë, 44321 Nantes, France.

E-mail addresses: benoit.hilloulin@ec-nantes.fr (B. Hilloulin), jean-baptiste. legland@ifsttar.fr (J.-B. Legland), elisabeth.lys@subatech.in2p3.fr (E. Lys), odile abraham@ifsttar.fr (O. Abraham), ahmed.loukili@ec-nantes.fr (A. Loukili), frederic grondin@ec-nantes.fr (F. Grondin), olivier.durand@ifsttar.fr (O. Durand), vincent. tournat@univ-lemans.fr (V. Tournat).
}

gases) can easily penetrate and deteriorate the material, leading in some cases to structural failure. Self-healing concrete could thus provide a means to achieving sizable savings by decreasing both the direct and indirect costs caused by repair works [1,2]. Selfhealing can occur naturally, without any particular additive, under favorable conditions with the continuous or periodic presence of water [3], by either a local reactivation of hydration [4-6] or the formation of healing products arising from reaction with the environment (mainly calcium carbonate from calcium in the concrete and carbonate ions contained in water) $[7,8]$. Some studies have reported the predominance of the precipitation phenomenon in ordinary concrete with a water-to-cement $(\mathrm{w} / \mathrm{c})$ ratio of around $0.4-0.5[8,9]$. Due to natural healing limitations, innovative engineering techniques have been developed to maximize healing; 
these include embedded capsules/vascular systems [10-14], and calcium carbonate-embedded bacteria production $[15,16]$.

Healing can be quantified through the use of various techniques. 2D optical microscopy offers the advantage of being fast and easily repeated [17]. Since this self-healing phenomenon may be more pronounced on the specimen surface and at certain locations rather than others, any techniques capable of quantifying healing products created inside the specimen or yielding global information are to be encouraged. Recently, X-ray computed tomography has been successfully applied $[18,19]$ yet the small voxel size (approx. $20 \mu \mathrm{m}$ ) has until now constituted a considerable limitation, especially when seeking to directly observe hydration-based healing products or small crystals.

In the aim of assessing the self-healing capability of inaccessible structures, non-destructive techniques have been developed for both practical and economic reasons. Ultrasonic pulse velocity has been employed to detect self-healing [20-25], although this technique is unable to assess the full extent of healing. Signal transmission measurements have also been used to quantify healing; however, this technique seems difficult to implement on larger structures due to inconsistency caused by coupling variability, with similar results being displayed among cracks larger than $100 \mu \mathrm{m}$ in width [25]. Recent studies have led to developing nonlinear ultrasonic methods that increase the sensitivity to damage [26,27]. Through the introduction of diffuse waves, large cracks/notches could be detected and crack evolution could be monitored [28-32], thus making it possible to highlight the sensitivity of diffuse ultrasound to a crack opening. Diffuse ultrasound has been applied to monitor the self-healing capacity of mortar cracks over time [33]. In fitting the envelope of the received signal, it becomes feasible to calculate both the arrival time of maximum energy (ATME) and effective diffusivity. These parameters however, and more specifically ATME, show great variations.

Coda Wave Interferometry (CWI), which relies on an analysis of the last part of the signal formed by multiple scattered waves, offers a highly sensitive method for detecting time-lapse perturbations on a propagation medium. CWI has been successfully adapted to concrete, which is a highly heterogeneous material, for determining nonlinear acoustic elastic properties [34] or detecting and locating small defects (i.e. holes several millimeters in diameter) $[35,36]$. By controlling for thermal bias [37], CWI can monitor propagation velocities with high precision $\left(10^{-3} \%\right.$ with respect to relative velocity variations) and good reproducibility in concrete; moreover, this technique provides information on the level of microcracking induced by loading [38]. The nonlinear acoustic effects of self-action have been reported in strongly nonlinear granular media [39]. In cracked solids, the nonlinear acoustic modulation method amplifies the signature of a defect when combined with an acoustic load provided by a pump source, in which case the sample is subjected to both a low-amplitude ultrasonic wave (known as a probe wave) and a large-amplitude wave at a lower frequency (known as a pump wave). If the sample contains a nonlinearity, caused for example by the presence of cracks or, more generally, contact-type defects, then the probe wave will become modulated due to variations in the local and surrounding effective elasticity (elastic modulus or acoustic dissipation), resulting from pump excitation [40-45]. Many distinct signal shapes may be input as pump and probe waves; however, the use of higherorder modulation side lobes or amplitude-modulated pump waves has shown greater sensitivity to the presence of cracks than other nonlinear modulation techniques [46]. By using nonlinear modulation and diffuse ultrasound to perform coda wave interferometry, we have recently proven that a very high level of precision can be obtained, hence enabling the detection of very small cracks as well as discriminating between different crack volumes $[47,48]$. Then throughout this paper, we describe the methodology we fol- lowed to increase nonlinear coda wave interferometry so that it can detect small cracks and can be used as a monitoring technique.

In addition, 3D image analysis for characterizing concrete cracking has been under development for a number of years. It is therefore possible to analyze fracture surfaces in conjunction with the interfacial transition zone composition [49]. Such 3D analyses can serve to obtain data in the form of surface topology, crack branching measurements and surface element phase classifications as inputs to the micromechanical modeling process [50]. Topological parameters like roughness can also be correlated with concrete performance, e.g. a new roughness parameter proportional to the $\mathrm{w} / \mathrm{c}$ ratio has been introduced in [51]. The 3D image analysis of a concrete surface thus appears to offer a promising field of research for purposes of generating geometric or topological data and supplementing other experimental techniques or providing input for numerical models.

The objective of this paper is to accurately assess the extent of self-healing in mortar specimens by use of two innovative nondestructive techniques, namely nonlinear CWI and 3D microscopy, and then confirm these observations using X-ray CT. Besides the complementarity of these methods we show their pertinence to assess partially healed specimens.

\section{Experimental design and methodology}

\subsection{Specimen preparation, healing conditions and coda - 3D microscope measurement procedures}

Two series of mortar samples with an equivalent geometry $(7 \mathrm{~cm} \times 7 \mathrm{~cm} \times 28 \mathrm{~cm}$ ) were mixed with a w/c ratio of 0.35 . The mortar mixtures consisted of $1350 \mathrm{~g}$ of $(0 / 2)$ sand, $450 \mathrm{~g}$ of (CEM II) Portland cement, $155 \mathrm{~g}$ of water and $8 \mathrm{~g}$ of superplasticizer (ChrysoFluid Optima 206). All preparations were carefully vibrated in order to minimize the amount of occluded air. After 1 day of curing under sealed conditions in an air-conditioned room at a temperature of $20^{\circ} \mathrm{C}$, the specimens were demolded and a notch $1.5 \mathrm{~cm}$ deep by $5 \mathrm{~mm}$ wide was cut at the center of all beams in order to initiate cracking. The specimens were further cured in tap water until an age of 3 days for Series 1 and 18 days for Series 2; they were then wrapped in aluminum foil in order to prevent drying shrinkage during the first coda measurements before cracking.

Next, some selected specimens from these two series were cracked using a crack mouth opening displacement (CMOD), as controlled by a three-point-bending test (once the aluminum foil had been removed from the central part). The final CMOD value before unloading was adjusted to obtain an actual crack width on the bottom part of the specimens equal to $50 \pm 5 \mu \mathrm{m}$. Coda measurements were then performed on the cracked specimens and the corresponding uncracked references before immersion in tap water for healing. The specimens were immersed at the ages of 1 week and 3 weeks respectively for Series 1 and 2. Three different healing durations were studied: 1 day, 3 days, and 7 days. After the desired healing period, the corresponding specimen was removed from water and wrapped in aluminum foil once again before conducting coda and $3 \mathrm{D}$ microscope tests over the subsequent 3 weeks. The various healing times and specimen labels are summarized in Table 1.

For the cracked specimens, 3D microscope measurements were performed during the 2 days following their removal from water. Coda measurements were recorded on all specimens while they were still wrapped in aluminum foil in order to reduce drying.

\subsection{Microscopic quantification of crack healing}

After completion of the cracking and healing processes, 3 zones of each cracked specimen were analyzed using a 3D optical micro- 
Table 1

Specimens used for CWI measurements.

\begin{tabular}{lll}
\hline Specimen label & Series (age at cracking (days)) & Immersion time (days) \\
\hline S1-R & 1 (uncracked) & 1 \\
S1-1 & $1(3)$ & 1 \\
S1-3 & $1(3)$ & 3 \\
S1-7 & $1(3)$ & 7 \\
S2-R & 2 (uncracked) & 1 \\
S2-1 & $2(18)$ & 1 \\
S2-3 & $2(18)$ & 3 \\
S2-7 & $2(18)$ & 7 \\
\hline
\end{tabular}

scope (Alicona Infinite Focus). These 3 zones were respectively chosen: along the bottom part to measure maximum crack width, in the middle, and at the top of the specimen to obtain indications regarding the healing phenomenon for various initial local crack widths. 3D images were reconstructed from a $20 \times$ magnification over an area of approximately $450 \times 600 \mu \mathrm{m}^{2}$, with a vertical accuracy of around $500 \mathrm{~nm}$ and a lateral resolution of around $1.5 \mu \mathrm{m}$. Automatic algorithms were applied in order to reconstruct 3D images from the set of 2D images recorded at various vertical positions. A quantification of the healing products formed inside the crack could thus be obtained over a large area. A conventional 2D optical microscope merely provides projected images, whose capacity to output information on the healing product inside the crack depends on the actual image field depth. Moreover, certain healing products located tens of micrometers beneath the surface can be distinguished with a 3D microscope while remaining unclear on some of the 2D microscopic images (see Fig. 1, where crystals are detected along the bottom of the image while they are invisible using a 2D microscope).

3D microscopes offer several tools normally employed for surface analyses that are capable of characterizing cracks and

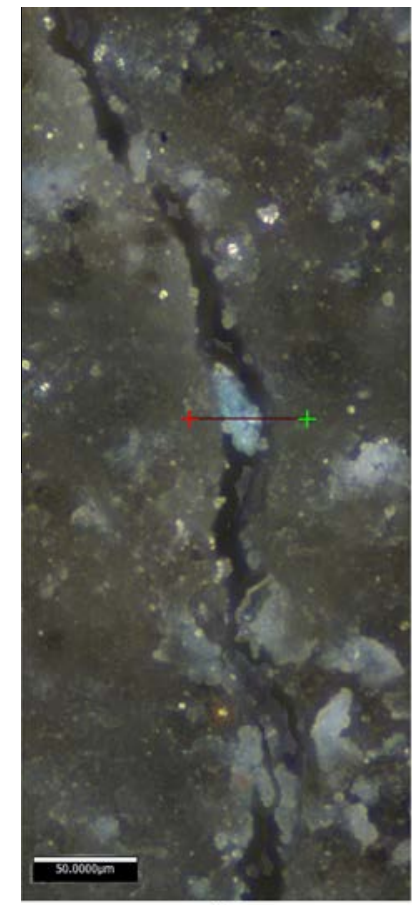

(a)

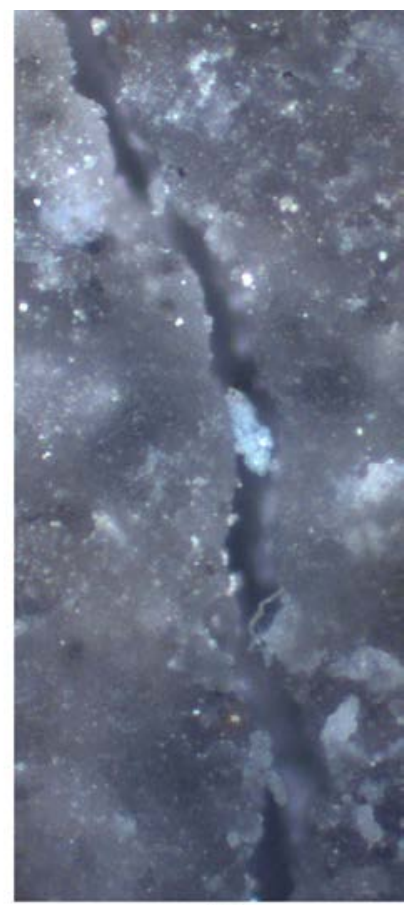

(b)
Fig. 1. Comparison of the microscopic images of a partially healed crack from specimen S2-3 with an initial local width of approx. $30 \mu \mathrm{m}$ in the middle of the specimen: a) reconstructed image from the 3D microscope and, b) image from a conventional 2D microscope (scale bar on the left hand side of image a) represents $50 \mu \mathrm{m})$. quantifying healing. In this study, we have focused on the global depth map and crack profile, local crack volumes and AbbottFirestone curves in order to derive a critical point of view regarding use of these techniques for monitoring crack evolution. Most of the crack pictures shown correspond to locations at the middle of the specimen; hence, the initial local crack width equaled roughly $30 \mu \mathrm{m}$.

\subsection{Acoustic measurements and data processing}

\subsubsection{Coda wave interferometry and diffuse ultrasonic parameter settings}

CWI measurements were conducted simultaneously on six specimens: two uncracked references, and four cracked or healed specimens. To carry out the CWI measurements, three piezoelectric transducers were glued onto each specimen. These consisted of: two transducers with an operating frequency range between 200 and $800 \mathrm{kHz}$ glued to the specimen around the notch for the probe wave excitation and detection, plus one frequency-swept piezoelectric ceramic transducer responsible for generating the largeramplitude acoustic pump wave at lower frequencies (typically in the range of $10-50 \mathrm{kHz}$ ) glued onto one side of each specimen in order to induce nonlinear acoustic modulation (see Fig. 2, $[47,48])$. During the test, the pump signal amplitude was automatically increased by steps ( 16 records per step were saved) through the power amplifier gain up to $60 \mathrm{~dB}$. A 2-h time span was chosen between the active pump periods, which lasted around $20 \mathrm{~min}$. More details about this set-up are given in [48].

\subsubsection{Signal processing: CWI results and diffuse ultrasonic parameters (ATME, $\xi$ )}

The probe signals corresponding to the various pump amplitudes were recorded from all specimens and were used for both CWI analyses and diffuse ultrasonic parameter calculations.

2.3.2.1. Diffuse ultrasonic parameters. The diffuse ultrasonic parameters were extracted from the intensity envelope of recorded signals. This envelope, shown in Fig. 3, is obtained by performing a low-pass filtered Hilbert transform of the signal [52]. Three parameters can be measured: Arrival Time of Maximum Energy (ATME) [33], damping coefficient $\xi$, and diffusion coefficient D. The process of estimating these three observables has been built as follows:

- first, the ATME is set equal to the time of the peak in the signal intensity envelope. For our study, the ATME lies in the range of several microseconds, and its measurement resolution is limited to the sampling frequency of the acquisition system $\left(f_{e}=5 \mathrm{MHz}\right)$.

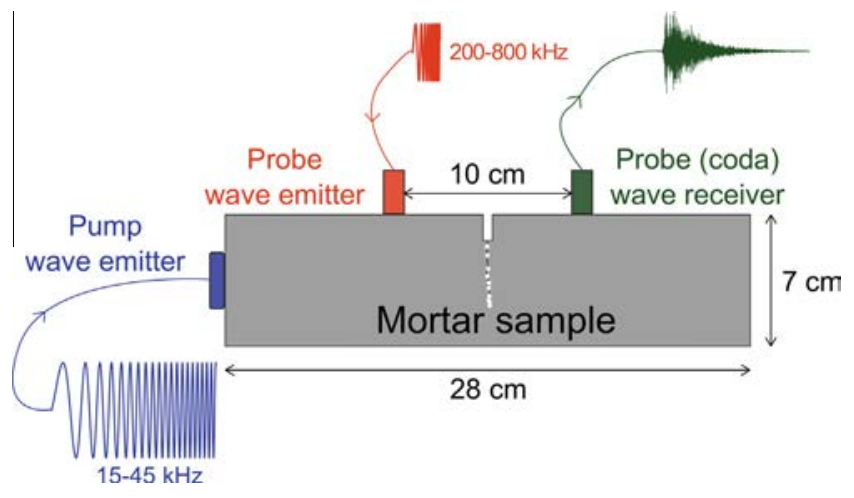

Fig. 2. Schematic diagram of the experimental set-up. 


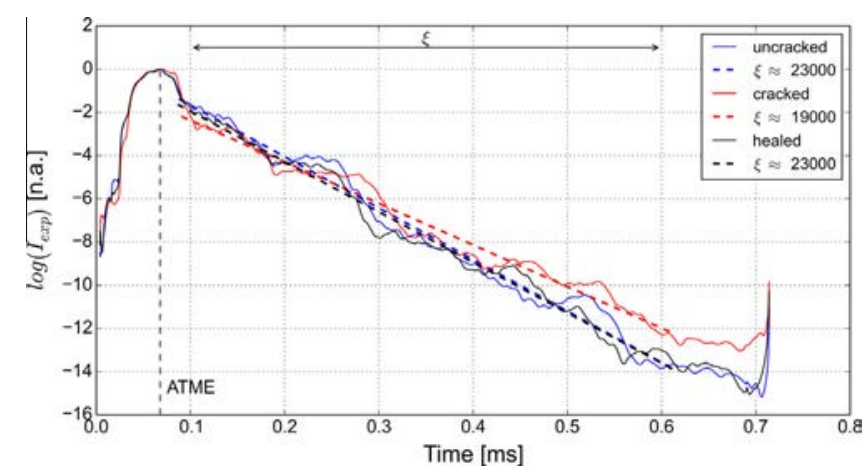

Fig. 3. Normalized intensity envelope of the coda recorded on the same sample for 3 damage states - The fitting of the damping coefficient appears to show that the cracked specimen is less damped, while the diffusivity and ATME do not reveal any significant variation.

- second, the damping coefficient is extracted by a linear regression of the decreasing part of the signal envelope, based on the solution to the diffusion equation in the bounded medium [28]:

$$
\begin{aligned}
I(x, y, z, t)= & I_{0} \\
& \times\left(1+2 \sum_{n=1}^{\infty} \cos \left(\frac{n \pi x_{0}}{L}\right) \cos \left(\frac{n \pi x}{L}\right) \exp \left(-D\left(n \frac{\pi}{L}\right)^{2}\right) t\right) \\
& \times\left(1+2 \sum_{n=1}^{\infty} \cos \left(\frac{n \pi y_{0}}{l}\right) \cos \left(\frac{n \pi y}{l}\right) \exp \left(-D\left(n \frac{\pi}{l}\right)^{2}\right) t\right) \\
& \times\left(1+2 \sum_{n=1}^{\infty} \cos \left(\frac{n \pi z_{0}}{h}\right) \cos \left(\frac{n \pi z}{h}\right) \exp \left(-D\left(n \frac{\pi}{h}\right)^{2}\right) t\right) \\
& \times \exp (-\xi \times \mathrm{t})
\end{aligned}
$$

where $L, l, h$ are the sample dimensions, $x_{0}, y_{0}, z_{0}$ the emitter position and $x, y, z$ the receiver position. The damping coefficient is then proportional to the logarithm of intensity: $\xi \propto \log (I)$. To correctly apply this linear regression, the data between $t=0.1 \mathrm{~ms}$ and $\mathrm{t}=0.6 \mathrm{~ms}$ (i.e. after ATME and before a low signal-to-noise ratio, see Fig. 3) are considered.
- third, the diffusion coefficient is obtained by minimizing the cost function [53]:

$\epsilon=\sum_{t}\left(\frac{\left|I_{\text {estim }}(t)-I_{\text {exp }}(t)\right|}{\operatorname{mean}\left(I_{\text {exp }}(t-\tau<t<t+\tau)\right)}\right)^{2}$

where $I_{\text {estim }}$ is calculated according to Equation (1), $I_{\text {exp }}$ is the intensity envelope of the experimental signal, and $\tau$ is a regularization parameter introduced to avoid any underestimation of the end of the signal compared to its beginning. The calculation parameters are set as follows: $I_{0}$ equals 1 by normalizing the signal with its own maximum, $\xi$ equals the value previously obtained from the linear regression, and $\tau$ is set equal to $50 / f_{e}$.

The aim of this process is to calculate the error (cost function) for each $\mathrm{D}$ defined beforehand between $D=10$ and $D=100$ with a step of $\delta D=1$ for the first loop of the script. In the second loop, $\delta D$ is equal to $+/-10 \%$ of $D_{\in \min }$ divided by 100 steps. However, despite the precision of our calculation, a 20\% variation in D induces practically no variation in the signal envelope; consequently, the diffusion coefficient cannot be used to accurately track the healing.

2.3.2.2. Coda Wave Interferometry (CWI). The CWI analyses have been performed using the well-known "stretching method" [27,31,33,54-56]. Two observables can be extracted from this analysis, i.e. $\varepsilon$ and $\mathrm{Kd}$, which are respectively the velocity variation and decorrelation, as calculated with the correlation coefficient [57], between two signals separated in time and with different medium states. This stretching method is applied on a late timewindow between $\mathrm{t}_{1}=0.1 \mathrm{~ms}$ and $\mathrm{t}_{2}=0.15 \mathrm{~ms}$ (Fig. 4).

$\varepsilon$ and $\mathrm{Kd}$ are sensitive to external stresses like temperature or mechanical force, as well as to the presence of cracks [48]. However, they both require that a healthy reference signal be recorded prior to damage. The method proposed herein consists of a nonlinear modulation of the coda waves by adding a low-frequency modulation pump, which has been previously tested for detecting cracks in glass plate samples [47]. This method seems able to effectively detect and characterize cracks at any time without the healthy reference signal. Furthermore, the nonlinear observables are more sensitive than the linear ones, and it is possible to detect and characterize the properties of different microcracks [48]. The
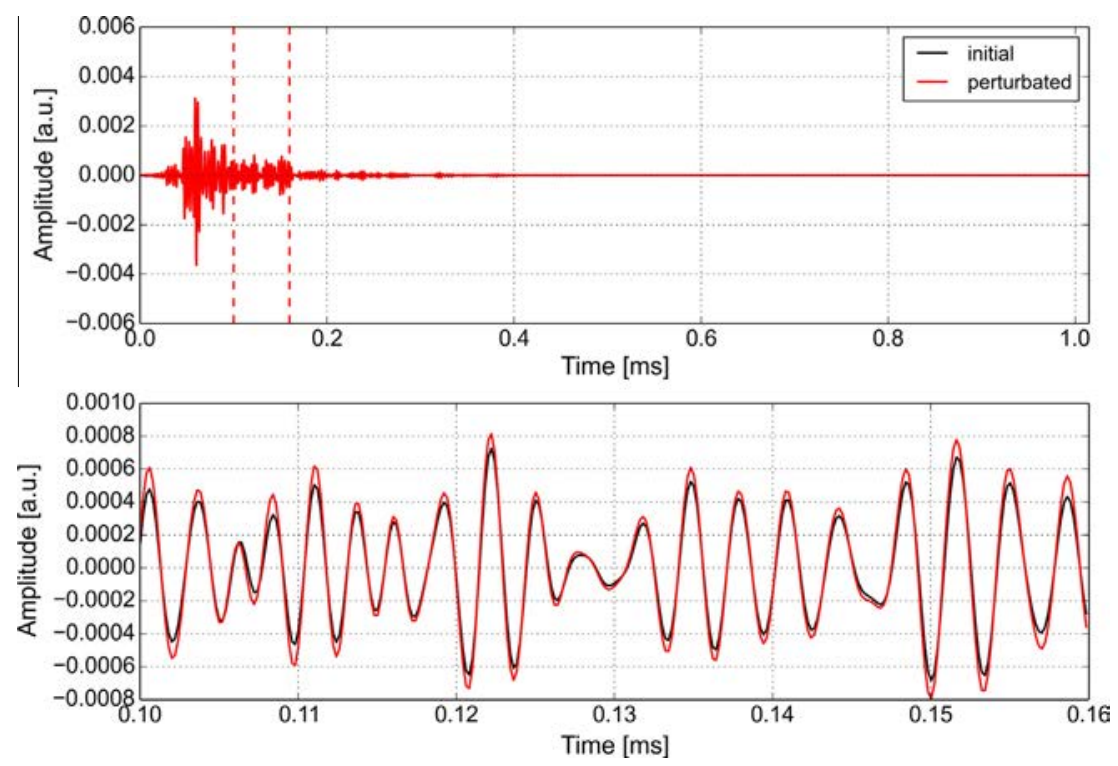

Fig. 4. Example of the acoustic pulse response of the sample (CODA), and close-up view of part of the signal where stretching is performed. 
sensitivity to pump amplitude decreases considerably after healing for all specimens, as illustrated in Fig. 5. For the cracked specimens, since the pump amplitude increases from 0 to $60 \mathrm{~dB}$, the propagation velocity actually decreases by up to $0.0025 \%$, while a smaller velocity variation can be observed on both the healed and uncracked specimens as pump amplitude increases (by less than $0.0005 \%)$. According to a quadratic fit of the remnant correlation evolution, the coefficient Kd vs. the local displacement near the pump closely matches the CWI data (Fig. 5b):

$\alpha_{K d} \propto u_{a c}^{2}$

where $u_{a c}$ is the acoustic displacement of the modulation pump. This parameter is measured with a laser vibrometer (Polytec OFV 503); the fitting parameter $\alpha_{K d}$ obtained for the fitting coefficient $\mathrm{Kd}$ can then be plotted vs. time, as illustrated in Fig. $5 \mathrm{~d}$. As the response of the velocity variation is negative, the extracted nonlinear observables are typically non classic hysteretic nonlinearities. These two nonlinear observables are directly concerned by the contact mechanics inside materials such as closed cracks and can serve as crack volume indicators.

\subsection{X-ray microtomography}

Following an air drying period lasting around 1 month, a number of specimens considered to be healed by CWI and 3D microscopy were sawn into volumes of $15 \mathrm{~mm} \times 15 \mathrm{~mm} \times 5 \mathrm{~cm}$ and subjected to X-ray microtomography in order to determine if healing products could be directly observed at a microscale using this technique. X-ray tomography thus serves to validate the initial measurements.

The $\mu-C T$ is composed of an X-ray generator with an operational voltage range of $40-150 \mathrm{kV}$ and an operational current range of 0 $250 \mu \mathrm{A}$. Our study has set the tube voltage at $89 \mathrm{kV}$ and the current intensity at $112 \mu \mathrm{A}$. The scanned object is placed on a rotation stage, and acquisition takes place over $360^{\circ}$ at a rate of one image per every $1 / 4$ of a degree. In all, 1440 radiographies are thus recorded by the flat panel sensor, which converts the electromagnetic signal transmitted throughout the sample into an electrical signal, while each radiography yields a measurement of X-ray absorption by the sample in a specific direction. The reconstruction was carried out with the XAct [58] software, which primarily relies on a back-projection method to reconstruct the linear attenuation coefficient for each voxel. It is possible therefore to produce the (a)

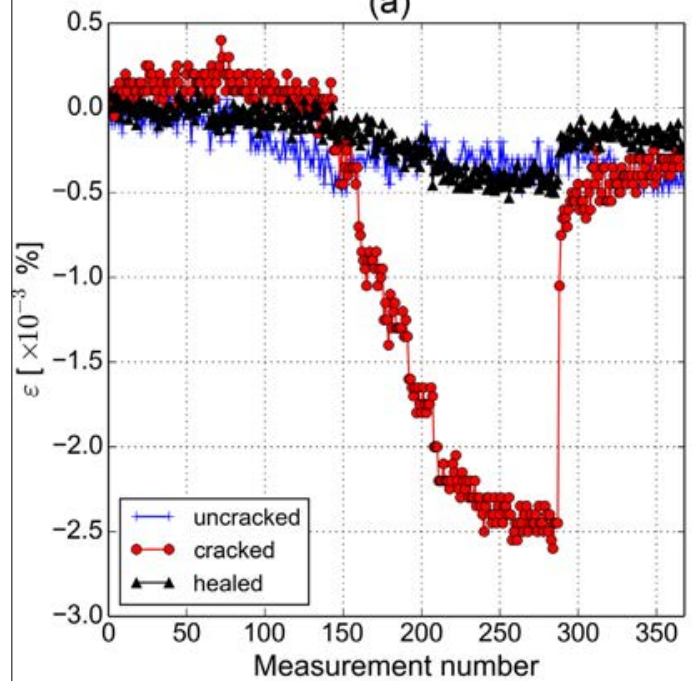

(c)

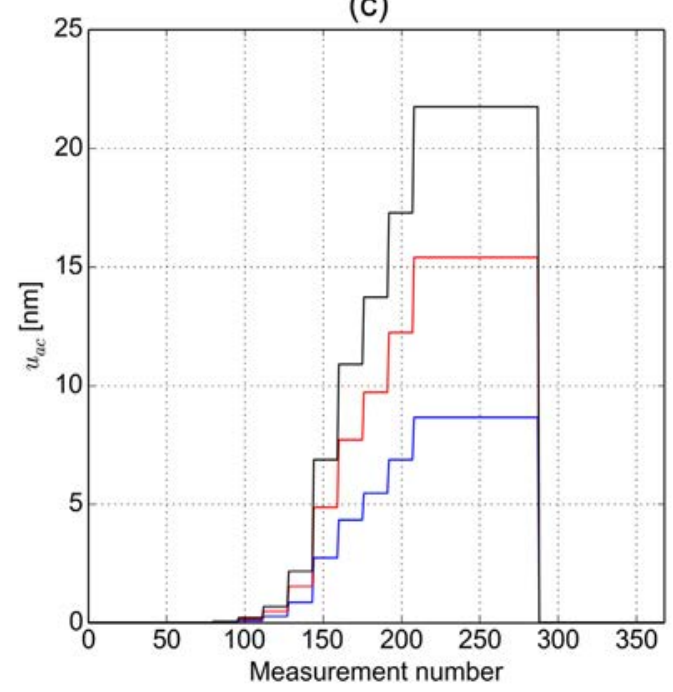

(b)

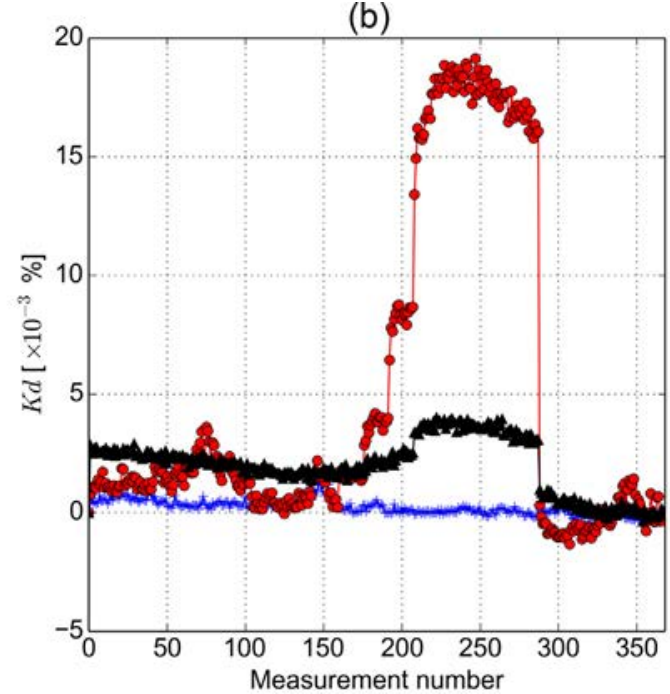

(d)

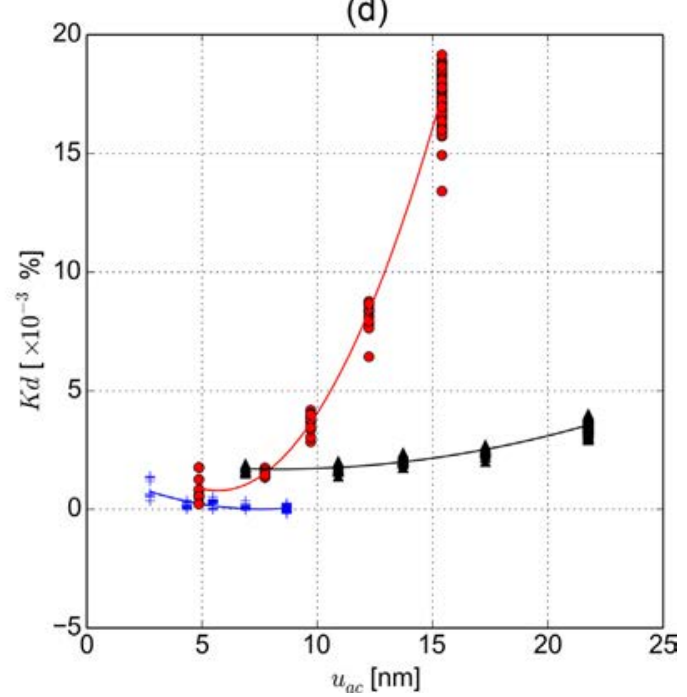

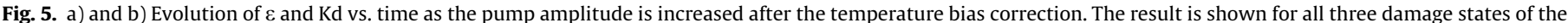

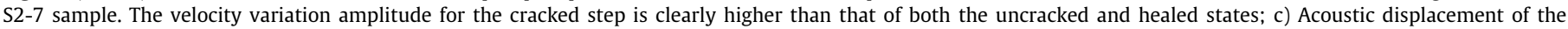
modulation pump; d) Quadratic fit of Kd measurement vs. the pump displacement measured by laser interferometer for cracked, healed and uncracked specimens. 
internal structure of the sample within a three-dimensional volume. In each projection direction, 5 consecutive scans are conducted, and averaged projection data are used for image reconstruction. The ultimate voxel size obtained equals roughly $12 \mu \mathrm{m}$.

Following this first step, our post-processing program (segmentation, mathematical morphology, 3D visualization or meshing of the segmented object) was developed with the Mevislab software [59]. Mevislab is a graphical language and allows building image processing by means of connecting subroutine blocks in a workspace. For the segmentation, we first binarized slices by selecting a threshold and then applied the "region growth" module to define the area to be segmented (e.g. cracks). This "region growth" algorithm [60] uses validation criteria to analyze the vicinity of a selected pixel in order to determine if it is part of the region. This process is continued in every direction ( $\mathrm{x}, \mathrm{y}$ and $\mathrm{z}$ ) until extra pixels can no longer be added.

An example of a CT slice image at one cross-section after reconstruction is shown in Fig. 6. High CT values, depicted in white or brighter colors, correspond to higher-density regions, whereas regions of low CT values, shown in black or darker colors, are associated with lower density. The crack is the black zone (zigzag) in the central part of the image. Small white granular regions, corresponding to high-density dehydrated particles, can also be distinguished

\section{Results and discussion}

\subsection{Healing quantification by nonlinear diffuse ultrasound}

\subsubsection{CWI results}

Fig. 7 summarizes all of the results obtained with the nonlinear modulation of the coda for $\alpha_{K d}$, which is the most sensitive of the observable parameters, with each point being a value of $\alpha_{K d}$ at a given time. In order to estimate the possible variations in the results, several non linear coda have been recorded for each state of the healing. The $\alpha_{K d}$ values are averaged based on the amount

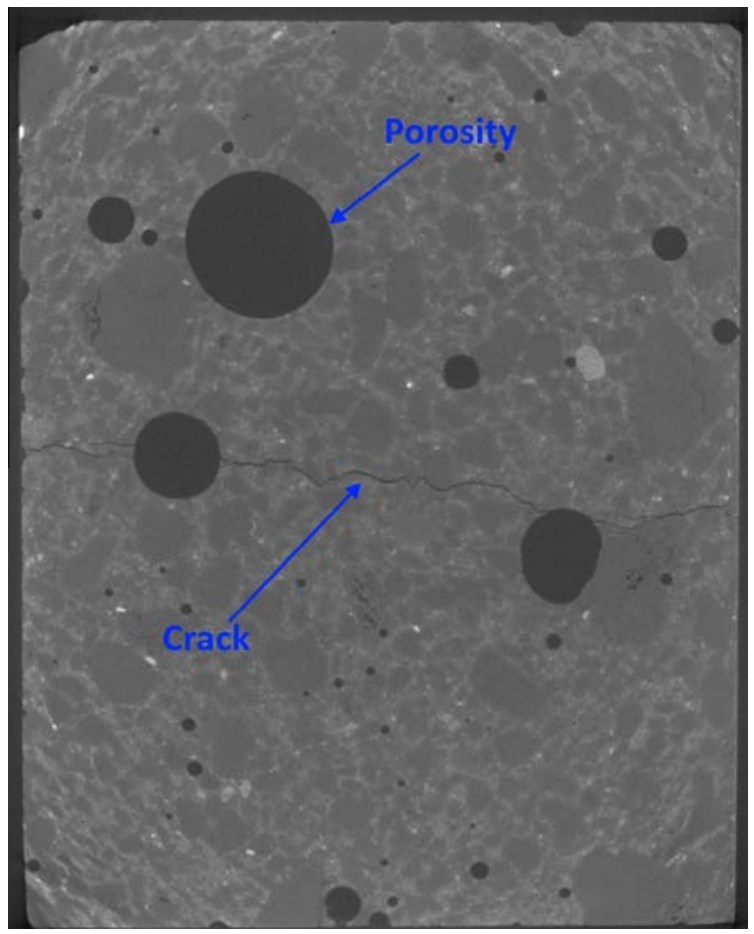

Fig. 6. Sliced X-ray CT image of a cracked reference mortar specimen (non representative because of a larger amount of voids).

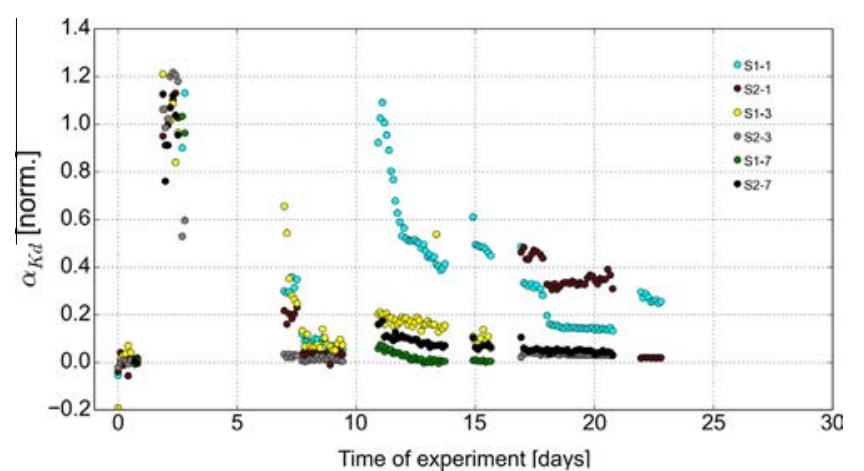

Fig. 7. Evolution in the nonlinear output $\alpha_{K d}$ vs. time: on day 0 , all specimens are uncracked; on day 3, all specimens are cracked; between days 7 and 24 , all specimens are healed (though with different healing proportions).

of time spent in water after cracking and the variations are presented as the standard deviation of the averaging. It should be noted that the intra-cycle measurement dispersion (see for example on Fig 5 b) is much smaller than variations over time during the whole experiment which are represented by error bars on Figs. 8 and 9. Calculation of the averaged $\overline{\alpha_{K d}}$ makes it possible to differentiate the various specimens according to their healing state. It appears that the longer the healing time, the smaller the value of $\overline{\alpha_{K d}}$ (Fig. 8). CWI can thus be used to monitor self-healing and efficiently distinguishes the various healing states. It can also be observed that specimens from Series 1 healed faster than those from Series 2. While a more detailed study needs to be carried out on this particular point, CWI results still indicate that specimens cracked before 1 week heal faster than those cracked after 2 weeks. This finding may be explained by the higher amount of dehydrated particles present at an early age. Upon crack formation, these particles might partly dissolve and thus lead to faster healing.

\subsubsection{Diffuse ultrasonic parameters and comparison with CWI parameters}

As illustrated in Fig. 9, diffuse ultrasonic parameters are in agreement with CWI measurements for the specimens from Series 2: like in [33], ATME decreases and diffusivity increases as the crack heals. For younger mortar specimens from Series 1 however, both ATME and $\xi$ reveal unexpected trends that may be explained by the fast evolution of the still hydrating material.

Better results, in terms of repeatability, can be obtained by selecting the experimental data after specimens have been out of water for a long time. This outcome could be explained by the drying of water remaining inside the crack.

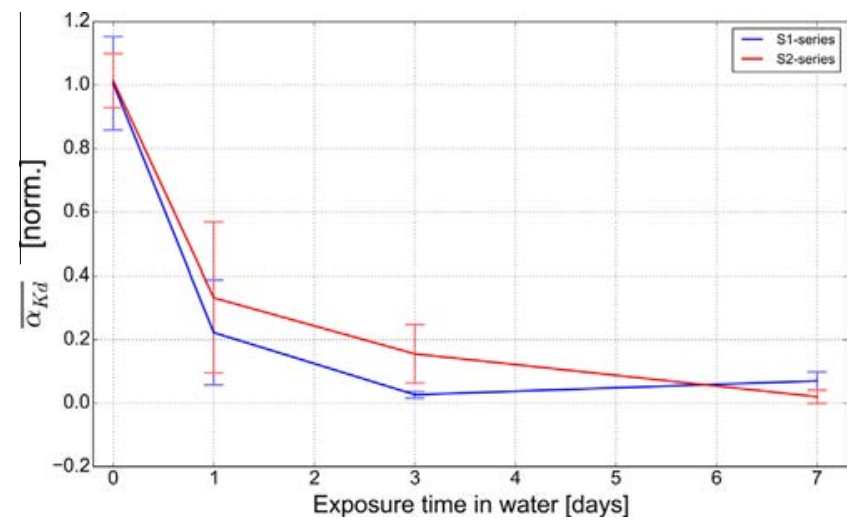

Fig. 8. Evolution in the average nonlinear parameter $\alpha_{K d}$ vs. healing duration for the two series of mortar specimens. 
(a)

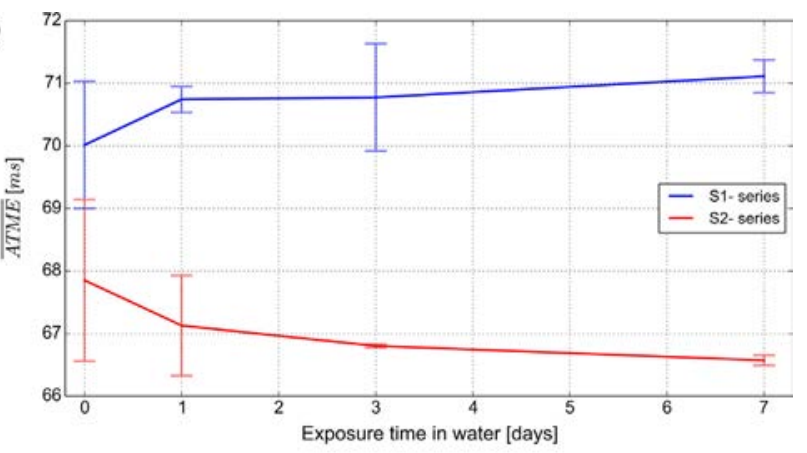

(b)

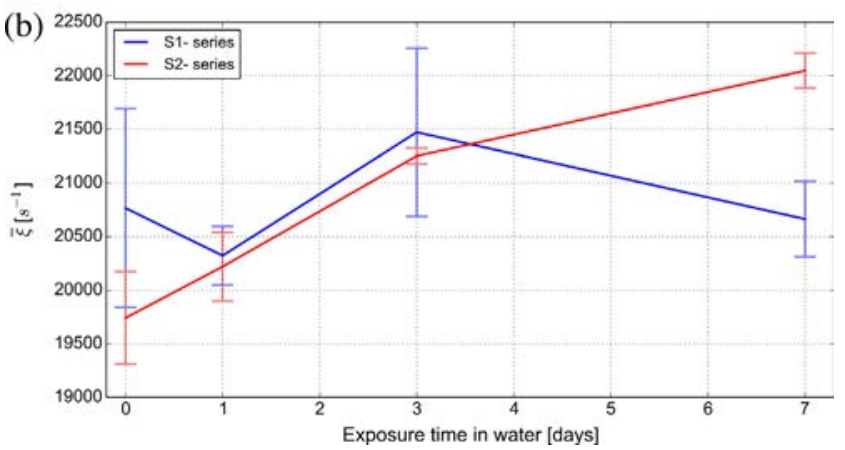

Fig. 9. Evolution in diffuse ultrasonic parameters for the two series subjected to healing vs. immersion time in water.

\subsection{D microscopy for crack filling monitoring}

The crack profile, apparent crack volume and Abbott-Firestone curves all provide information about crack healing.
First of all, a local crack profile indicates the presence of healing products developing inside the initial crack. These products can be easily detected on depth maps that compare initial and healed states, as illustrated in Fig. 10. Although the specimen surface is unpolished, depth decreases due to healing are easily observable and drop in value from between 50 and $100 \mu \mathrm{m}$ to close to 0 after healing. Positive values can sometimes be found should the healing product exit from the crack. Such was observed on specimens with longer healing times (lasting several weeks) that were not presented in this study. Mean crack profiles over a typical width of $200 \mu \mathrm{m}$, computed perpendicularly to the crack direction, help quantify global crack filling. Let's note that the local crack width at the surface decreases at the same time as depth is decreasing in the entire crack due to the precipitation of healing products. Nonetheless, the choice of profile location and measurement sensitivity to the profile direction (ideally perpendicular to the crack) both potentially make this method non-representative and prone to errors. The user must carefully compare the two exact same profiles, turning profile analysis into a time-consuming process for monitoring purposes.

Moreover, the apparent crack volume can be estimated using the coordinates at each point of the reconstructed images. After selecting a horizontal plane with an altitude a bit below the specimen surface (leading to a $2 \mathrm{D}$ top view that corresponds to the local crack area, as illustrated in Fig. 11a), the crack volume under this plane, called Vc, can be calculated. Once the projected area has been normalized, the apparent crack volume ratio, as calculated by dividing the normalized apparent volume after an immersion time $\mathrm{t}$ by the initial normalized apparent crack volume, provides an overall indication of the healing state of a specimen, as illustrated in Fig. 11b. From microscopic investigations conducted at the center of specimens, only a very partial healing actually has time to occur during the first day of immersion, since the apparent crack volumes are close to their initial values. After 3 days of immersion

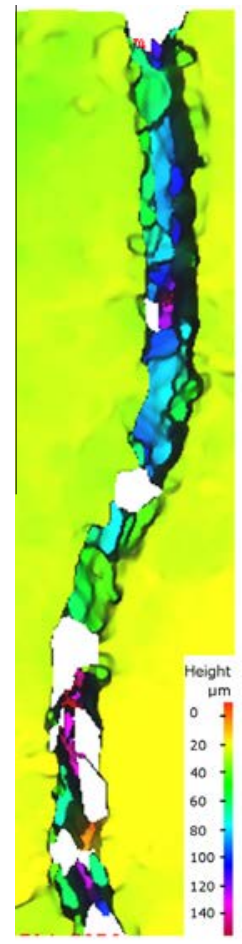

(a)

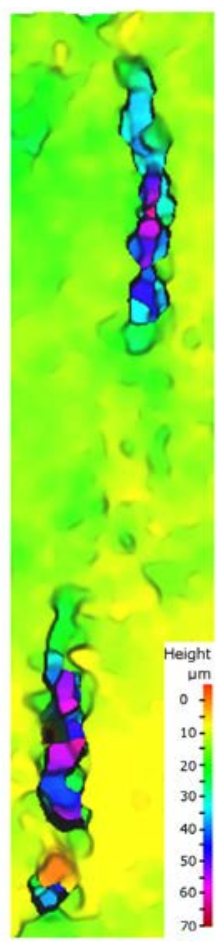

(b)

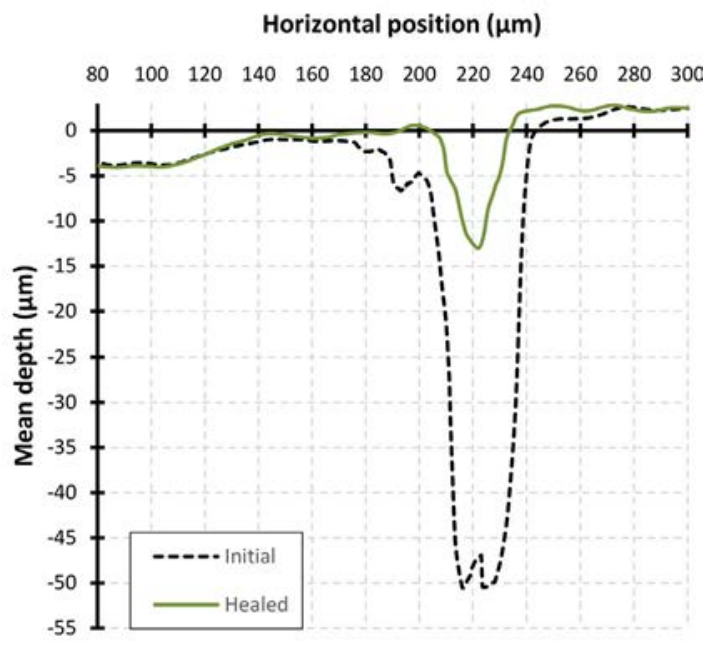

(c)

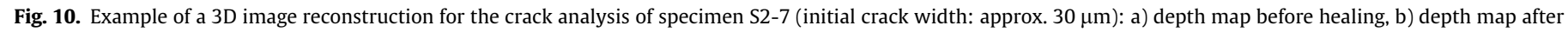
healing (with healing products filling the central part of the picture), c) the corresponding evolution in the mean crack depth profile. 


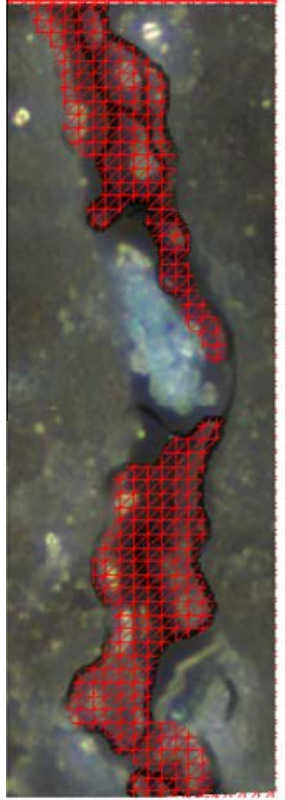

(a)

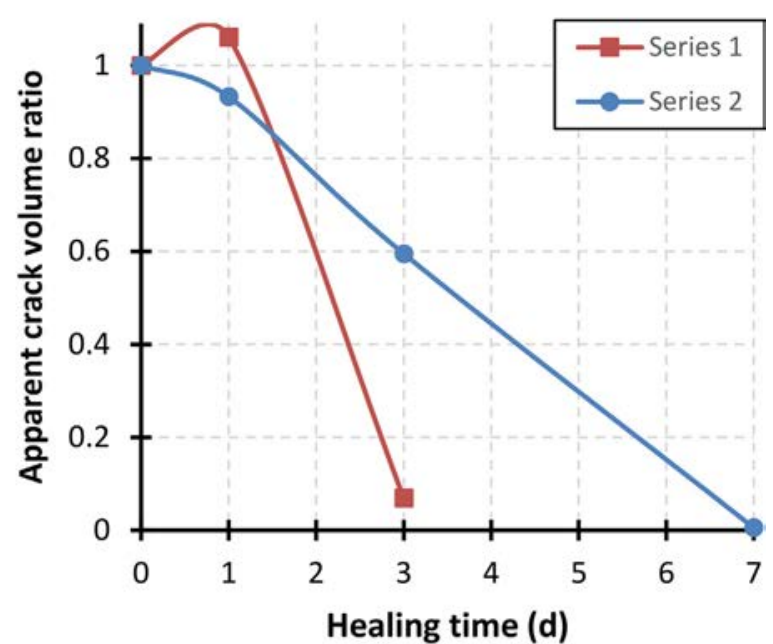

(b)

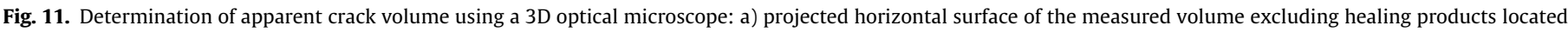
at the surface, and b) normalized apparent crack volume for the specimens.

however, the healing has progressed: it has indeed occurred at some of the locations illustrated in Fig. 10 for the Series 2 specimen and is nearly complete for the Series 1 specimen. Crack volume ratios thus decrease over time as the cracks fill with healing products.

Moreover, the Abbott-Firestone curve of an entire picture offers a quick assessment of crack characteristics and quantifies the healing on larger zones of interest, as illustrated in Fig. 12a. The part of the curve depicting the crack can be approximately determined as the part where the derivative of the curve starts to significantly increase (Fig. 12b), which corresponds to a quick increase in the depth associated with image pixels. Depending on how crack width compares to picture width, the portion of the AbbottFirestone curves corresponding to the crack thus lie between 90 and $95 \%$ and $100 \%$ of the cumulative depths in this study. The healing of a specimen changes the Abbot-Firestone curve that corresponds to a picture taken at the same location, as illustrated in Fig. 12a. It is interesting to note that healing products are created all along the observable crack depth (around 50 and $60 \mu \mathrm{m}$ for all cracks in this study), which is visible on the crack profile (Fig. 10c). Hence, the Abbott-Firestone curves yield a similar observation with respect to crack filling as the volume determination technique, yet this technique features the advantage of being very quick to generate and analyze (integration of the Abbott-Firestone curve should produce a single coefficient related to crack volume).

\subsection{Supplements from X-ray microtomography}

The X-ray CT observations have revealed the formation of healing products inside the crack near the surface within a range of approximately $0.5 \mathrm{~mm}$ from the surface to the interior of the specimen, which corroborates the observation using the two other nondestructive techniques. As illustrated in Fig. 13, small bridges can be detected through the crack as they locally decrease the gray intensity inside the crack. Even after a very limited immersion time of a few days, healing can still occur therefore in a narrow crack

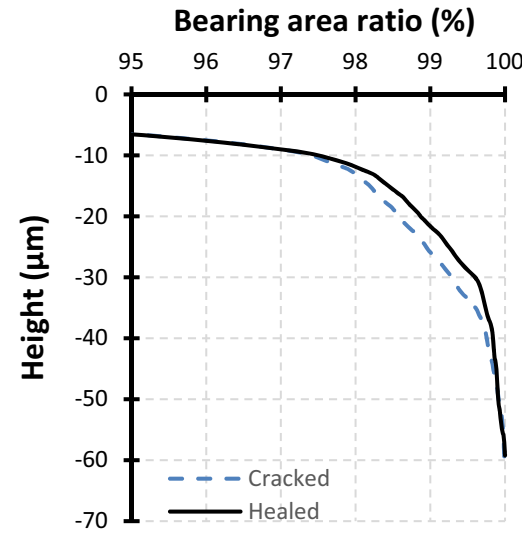

(a)

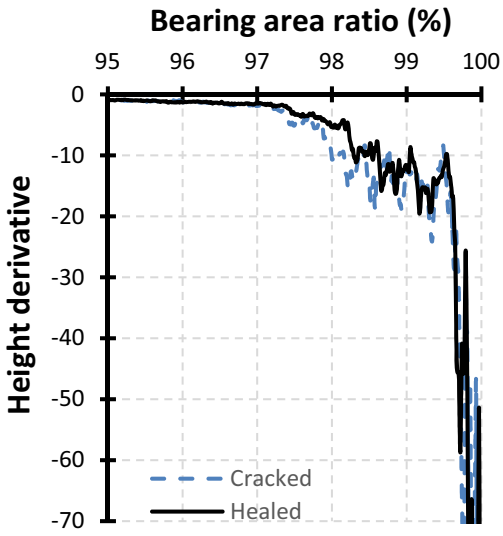

(b)

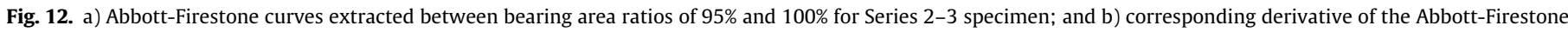
curves. 


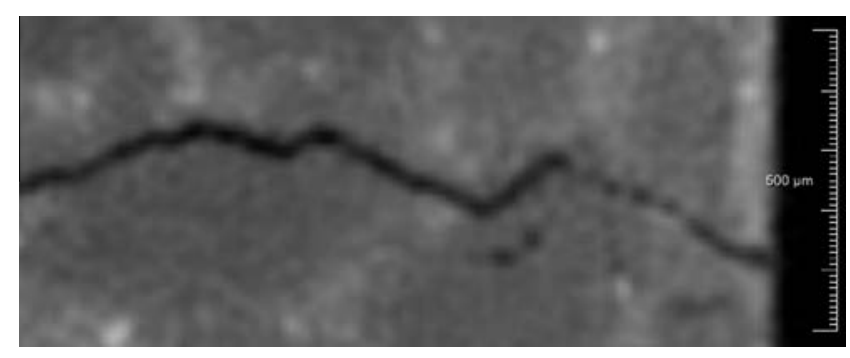

Fig. 13. X-ray CT slice after a 3 days healing period with a voxel size of $12 \mu \mathrm{m}$. Healing products are detectable at the right end side, near the crack surface.

with a width of 30-50 $\mu \mathrm{m}$. Let's also note that these healing products display a different appearance than in $[18,19]$. This difference could be explained by their distinct nature: though a specific study was not conducted, Fukuda et al. most likely observed for the most part calcite or portlandite formation (owing to the constant thickness over large zones), while in our study the appearance of local bridges suggests the formation of hydration products ( $\mathrm{CSH}$, ettringite or portlandite).

\section{Conclusion and outlook}

In conclusion, CWI and 3D microscope measurements present the same trends and both seem sensitive to partial healing which could be helpful for in situ healing characterization. For these two techniques, the healing of younger specimens from Series 1 is faster than the healing of older Series 2 specimens which means that the methods developed are sensitive enough to distinguish the healing kinetics of two mortars with the same composition but cracked at different ages (e.g. 3 days and 18 days). It appears that CWI results are very sensitive at the beginning of healing: for specimens with just one day of healing, CWI parameters are already smaller than those of the corresponding cracked specimens, while the healing indices can hardly be exhibited from either 3D volume measurements or Abbott-Firestone curves for this healing period (only the formation of small crystals on the top part of the crack indicates that healing has begun). More precisely, nonlinear hysteretic observables extracted from the CWI decrease sharply during the first 3 days of healing, due to the quick creation of healing products bridging the crack. On the other hand, 3D images reconstructed from a $20 \times$ magnification over an area of approximately $450 \times 600 \mu \mathrm{m}^{2}$ in a reasonable amount of time, clearly show the spatial disparity of healing. We showed that posttreatment algorithms leading to the apparent cracked volume or the Abott-Firestone curves (for bearing area ratios higher than 90\%) are sensitive to healing and supplement global nondestructive measurements. Crack healing has been confirmed by $\mathrm{X}$-ray CT as some bridges can be locally observed near the surface of the specimen with a voxel size of $12 \mu \mathrm{m}$. In our study, CWI seems to be more appropriate than diffuse ultrasonic parameters in the case of young mortars from Series 1, which are still evolving due to ongoing hydration.

Nonlinear CWI, 3D microscopy and X-ray $\mu$-CT all appear therefore to be very valuable techniques for monitoring the healing of cementitious materials regardless of the concrete formulation. The main difference between these techniques is that using nonlinear coda wave interferometry, the whole structure could be explored and the nonlinearities from the cracks would be emphasized. On the other hand, if 3D microscopy is used a nondestructive way, only the specimen surface (or the surface inside the cracks) can be analyzed. However combining them would provide highly useful local and global information at different scales. Several applications of these techniques to larger concrete specimens or outdoor structures could likely be developed for durability purposes.

\section{Acknowledgments}

The authors would like to thank Michel Grasset (IFSTTAR MAST, SMC) for assisting with the 3D microscope measurements. Financial support from GIS LiRGeC (France's Loire Valley Region) towards Benoit Hilloulin's thesis work is also gratefully acknowledged. Part of this work concerning X-ray tomography has been supported by the CPER, including funding from the Regional Council of France's Loire Valley Region, the "Conseil général de LoireAtlantique", the French government and the FEDER (European Union).

\section{References}

[1] K. van Breugel, Self-healing concepts in civil engineering for sustainable solutions: potential and constraints, in: Proceedings of the Second International Conference on Self-Healing Materials, 2009.

[2] M. de Rooij, K. Van Tittelboom, N. De Belie, E. Schlangen (Eds.), Self-Healing Phenomena in Cement-Based Materials, Springer, Netherlands, 2013.

[3] Y. Yang, M.D. Lepech, E.-H. Yang, V.C. Li, Autogenous healing of engineered cementitious composites under wet-dry cycles, Cem. Concr. Res. 39 (5) (2009) 382-390.

[4] S. Granger, A. Loukili, G Pijaudier-Cabot, G. Chanvillard, Experimental characterization of the self-healing of cracks in an ultra high performance cementitious material: mechanical tests and acoustic emission analysis, Cem. Concr. Res. 37 (4) (2007) 519-527.

[5] B. Hilloulin, F. Grondin, M. Matallah, A. Loukili, Modelling of autogenous healing in ultra high performance concrete, Cem. Concr. Res. 61 (2014) 64-70.

[6] H. Huang, G. Ye, D. Damidot, Characterization and quantification of selfhealing behaviors of microcracks due to further hydration in cement paste, Cem. Concr. Res. 52 (2013) 71-81.

[7] C.A. Clear, The Effect of Autogenous Healing Upon Leakage of Water Through Cracks in Concrete. Technical Report, Cement and Concrete Association, 1985.

[8] C. Edvardsen, Water permeability and autogenous healing of cracks in concrete, ACI Mater. J. 96 (4) (1999) 448-454.

[9] H. Ranaivomanana, J. Verdier, A. Sellier, Xavier Bourbon, Sealing process induced by carbonation of localized cracks in cementitious materials, Cement Concr. Compos. 37 (2013) 37-46.

[10] B. Hilloulin, K. Van Tittelboom, E. Gruyaert, N. De Belie, A. Loukili, Design of polymeric capsules for self-healing concrete, Cement Concr. Compos. 55 (2015) 298-307.

[11] C. Dry, W. McMillan, Three-part methylmethacrylate adhesive system as an internal delivery system for smart responsive concrete, Smart Mater. Struct. 5 (3) (1996) 297

[12] V.C. Li, Y.M. Lim, Y.-W. Chan, Feasibility study of a passive smart self-healing cementitious composite, Compos. B Eng. 29 (6) (1998) 819-827.

[13] H. Mihashi, Y. Kaneko, T. Nishiwaki, K. Otsuka, Fundamental study on development of intelligent concrete characterized by self-healing capability for strength, Trans. Jpn. Concr. Inst. 22 (2000) 441-450.

[14] K. Van Tittelboom, N. De Belie, D. Van Loo, P. Jacobs, Self-healing efficiency of cementitious materials containing tubular capsules filled with healing agent, Cement Concr. Compos. 33 (4) (2011) 497-505.

[15] V. Wiktor, H.M. Jonkers, Quantification of crack-healing in novel bacteriabased self-healing concrete, Cement Concr. Compos. 33 (7) (2011) 763-770.

[16] J. Wang, K. Van Tittelboom, N. De Belie, W. Verstraete, Use of silica gel or polyurethane immobilized bacteria for self-healing concrete, Constr. Build. Mater. 26 (1) (2012) 532-540.

[17] K. Van Tittelboom, E. Gruyaert, H. Rahier, N. De Belie, Influence of mix composition on the extent of autogenous crack healing by continued hydration or calcium carbonate formation, Constr. Build. Mater. 37 (2012) 349-359.

[18] D. Fukuda, Y. Nara, Y. Kobayashi, M. Maruyama, M. Koketsu, D. Hayashi, H. Ogawa, K. Kaneko, Investigation of self-sealing in high-strength and ultra-lowpermeability concrete in water using micro-focus X-ray ct, Cem. Concr. Res. 42 (11) (2012) 1494-1500.

[19] D. Fukuda, Y. Nara, D. Hayashi, H. Ogawa, K. Kaneko, Influence of fracture width on sealability in high-strength and ultra-low-permeability concrete in seawater, Materials 6 (7) (2013) 2578-2594.

[20] Y. Abdel-Jawad, R. Haddad, Effect of early overloading of concrete on strength at later ages, Cem. Concr. Res. 22 (5) (1992) 927-936.

[21] S. Jacobsen, J. Marchand, H. Hornain, Sem observations of the microstructure of frost deteriorated and self-healed concretes, Cem. Concr. Res. 25 (8) (1995) $1781-1790$.

[22] S. Jacobsen, J. Marchand, L. Boisvert, Effect of cracking and healing on chloride transport in OPC concrete, Cem. Concr. Res. 26 (6) (1996) 869-881.

[23] M. Sahmaran, S.B. Keskin, G. Ozerkan, I.O. Yaman, Self-healing of mechanically-loaded self consolidating concretes with high volumes of fly ash, Çem. Concr. Compos. 30 (10) (2008) 872-879. 
[24] W. Zhong, W. Yao, Influence of damage degree on self-healing of concrete, Constr. Build. Mater. 22 (6) (2008) 1137-1142.

[25] C. Aldea, W. Song, J. Popovics, S. Shah, Extent of healing of cracked normal strength concrete, J. Mater. Civil Eng. 12 (2000) 92-96.

[26] P.B. Nagy, Fatigue damage assessment by nonlinear ultrasonic materials characterization, Ultrasonics 36 (1998) 375-381.

[27] A. Novak, M. Bentahar, V. Tournat, R. El Guerjouma, L. Simon, Nonlinear acoustic characterization of micro-damaged materials through higher harmonic resonance analysis, NDT E Int. 45 (1) (2012) 1-8.

[28] S. Ramamoorthy, Y. Kane, J.A. Turner, Ultrasound diffusion for crack depth determination in concrete, in: W. Arnold, S. Hirsekorn (Eds.), Acoustical Imaging, Acoustical Imaging, vol. 27, Springer, Netherlands, 2004, pp. 121128.

[29] W. Punurai, J. Jarzynski, J. Qu, K.E. Kurtis, L.J. Jacobs, Characterization of dissipation losses in cement paste with diffuse ultrasound, Mech. Res, Commun. 34 (3) (2007) 289-294.

[30] F. Deroo, L.J. Jacobs, J.Y. Kim, J. Qu, K. Sabra, Damage detection in concrete using diffuse ultrasound measurements, AIP Conf. Proc. 1211 (1) (2010) 15091516.

[31] A. Quiviger, C. Payan, J.-F. Chaix, V. Garnier, J. Salin, Effect of the presence and size of a real macro-crack on diffuse ultrasound in concrete, NDT E Int. 45 (1) (2012) 128-132.

[32] A. Quiviger, A. Girard, C. Payan, J.F. Chaix, V. Garnier, J. Salin, Influence of the depth and morphology of real cracks on diffuse ultrasound in concrete: a simulation study, NDT E Int. 60 (2013) 11-16.

[33] C.-W. In, R. Brett Holland, J.-Y. Kim, K.E. Kurtis, L.F. Kahn, L.J. Jacobs, Monitoring and evaluation of self-healing in concrete using diffuse ultrasound, NDT E Int. 57 (0) (2013) 36-44.

[34] C. Payan, V. Garnier, J. Moysan, P.A. Johnson, Determination of third order elastic constants in a complex solid applying coda wave interferometry, Appl, Phys. Lett. 94 (1) (2009).

[35] E. Larose, T. Planes, V. Rossetto, L. Margerin, Locating a small change in a multiple scattering environment, Appl. Phys. Lett. 96 (20) (2010).

[36] D.P. Schurr, J.-Y. Kim, K.G. Sabra, L.J. Jacobs, Damage detection in concrete using coda wave interferometry, NDT E Int. 44 (8) (2011) 728-735.

[37] Y. Zhang, O. Abraham, V. Tournat, A. Le Duff, B. Lascoup, A. Loukili, F. Grondin, O. Durand, Validation of a thermal bias control technique for coda wave interferometry (cwi), Ultrasonics 53 (3) (2013) 658-664.

[38] Y. Zhang, O. Abraham, F. Grondin, A. Loukili, V. Tournat, A. Le Duff, B. Lascoup, O. Durand, Study of stress-induced velocity variation in concrete under direct tensile force and monitoring of the damage level by using thermallycompensated coda wave interferometry, Ultrasonics 52 (8) (2012) 1038-1045.

[39] V. Tournat, V. Gusev, Nonlinear effects for coda-type elastic waves in stressed granular media, Phys. Rev. E 80 (2009) 011306.

[40] D. Donskoy, A. Sutin, A. Ekimov, Nonlinear acoustic interaction on contact interfaces and its use for nondestructive testing, NDT E Int. 34 (4) (2001) 231 238.

[41] K. Van Den Abeele, J. De Visscher, Damage assessment in reinforced concrete using spectral and temporal nonlinear vibration techniques, Cem. Concr. Res. 30 (9) (2000) 1453-1464.
[42] K. Van Den Abeele, J. Carmeliet, J.A. Ten Cate, P.A. Johnson, Nonlinear elastic wave spectroscopy (news) techniques to discern material damage, part ii: single-mode nonlinear resonance acoustic spectroscopy, Res. Nondestr. Eval. 12 (1) (2000) 31-42.

[43] K. Van Den Abeele, A. Sutin, J. Carmeliet, P.A. Johnson, Micro-damage diagnostics using nonlinear elastic wave spectroscopy (news), NDT E Int. 34 (4) (2001) 239-248.

[44] V. Zaitsev, V. Nazarov, V. Gusev, B. Castagnede, Novel nonlinear-modulation acoustic technique for crack detection, NDT E Int. 39 (3) (2006) 184-194.

[45] V. Zaitsev, L.A. Matveev, A.L. Matveyev, On the ultimate sensitivity of nonlinear-modulation method of crack detection, NDT E Int. 42 (7) (2009) 622-629.

[46] V. Zaitsev, L.A. Matveev, A.L. Matveyev, Elastic-wave modulation approach to crack detection: comparison of conventional modulation and higher-order interactions, NDT E Int. 44 (1) (2011) 21-31.

[47] Y. Zhang, V. Tournat, O. Abraham, O. Durand, S. Letourneur, A. Le Duff, B. Lascoup, Nonlinear mixing of ultrasonic coda waves with lower frequencyswept pump waves for a global detection of defects in multiple scattering media, J. Appl. Phys. 113 (6) (2013) 064905.

[48] B. Hilloulin, Y. Zhang, O. Abraham, A. Loukili, F. Grondin, O. Durand, V. Tournat, Small crack detection in cementitious materials using nonlinear coda wave modulation, NDT E Int. 68 (2014) 98-104.

[49] S. Mindess, S. Diamond, Sem investigations of fracture surfaces using stereo pairs: I. Fracture surfaces of rock-cement paste composite specimens, Cem. Concr. Res. 22 (4) (1992) 678-688.

[50] A.B. Nichols, D.A. Lange, 3D surface image analysis for fracture modeling of cement-based materials, Cem. Concr. Res. 36 (6) (2006) 1098-1107.

[51] T. Ficker, D. Martisek, H.M. Jennings, Roughness of fracture surfaces and compressive strength of hydrated cement pastes, Cem. Concr. Res. 40 (6) (2010) 947-955.

[52] R. Bracewell, The Fourier Transform and Its Applications, 1986.

[53] Mathieu Chekroun, Caractérisation mécanique des premiers centimètres du béton avec des ondes de surface (Ph.D, thesis), Ecole Centrale de Nantes, 2008.

[54] R. Snieder, Coda wave interferometry and the equilibration of energy in elastic media, Phys. Rev. E 66 (2002) 046615.

[55] R.L. Weaver, C. Hadziioannou, E. Larose, M. Campillo, On the precision of noise correlation interferometry, Geophys. J. Int. 185 (3) (2011) 1384-1392. 23.

[56] O.I. Lobkis, R.L. Weaver, Coda-wave interferometry in finite solids: recovery of p-to-s conversion rates in an elastodynamic billiard, Phys. Rev. Lett. 90 (2003) 254302. 24, 47, 50 .

[57] J.L. Rodgers, W.A. Nicewander, Thirteen ways to look at the correlation coefficient, Am. Stat. 42 (1988) 59-66.

58] XAct. <http://www.rxsolutions.fr/>.

[59] Mevislab. <http://www.mevislab.de/>

[60] N. Mesanovic, H. Huseinagic, S. Kamenjakovic, Automatic region based segmentation and analysis of lung volumes from ct images, Int. J. Comput. Sci. Technol. 4 (2013) 48-51. 